\title{
Molecular Composition and Antibacterial Effect of Five Essential Oils Extracted from Nigella sativa L. Seeds against Multidrug- Resistant Bacteria: A Comparative Study
}

\author{
Mohammed Dalli (D, ${ }^{1}$ Salah-eddine Azizi, ${ }^{1}$ Hind Benouda, ${ }^{2}$ Ali Azghar, ${ }^{3}$ Maroua Tahri, ${ }^{3}$ \\ Boufalja Bouammali, ${ }^{2}$ Adil Maleb, ${ }^{3}$ and Nadia Gseyra ${ }^{1}$ \\ ${ }^{1}$ Laboratoire de Bioressources, Biotechnologie, Ethnopharmacologie et Santé, Equipe de Physiologie et Ethnopharmacologie, \\ Université Mohammed Premier, Faculté des Sciences, Bloc de Recherche 1ème étage 60 000, Oujda, Morocco \\ ${ }^{2}$ Laboratoire de Chimie Organique, Macromoléculaire et Produits Naturels, Université Mohammed Premier, Faculté des Sciences, \\ Bloc de Recherche 2ème étage 60 000, Oujda, Morocco \\ ${ }^{3}$ Laboratoire de Microbiologie, Centre Hospitalier Universitaire (CHU), Oujda, Morocco \\ Correspondence should be addressed to Mohammed Dalli; m.dalli@ump.ac.ma
}

Received 2 December 2020; Revised 18 February 2021; Accepted 6 March 2021; Published 15 March 2021

Academic Editor: Muhammad Jahangir Hossen

Copyright (C 2021 Mohammed Dalli et al. This is an open access article distributed under the Creative Commons Attribution License, which permits unrestricted use, distribution, and reproduction in any medium, provided the original work is properly cited.

\begin{abstract}
Nigella sativa L. (NS) and its volatile compounds are well known for their broad spectrum of effects. This study aimed to investigate the variability of the chemical composition and the in vitro antibacterial activity of five essential oils (Eos) originated from Morocco, Saudi Arabia, Syria, India, and France. These five samples were grown under different edaphic and climatic conditions. The agar diffusion method and microdilution method in 96-well plates were used to test the sensitivity of multidrugresistant strains clinically isolated from patients (methicillin-resistant Staphylococcus aureus, Escherichia coli, Pseudomonas aeruginosa, and Acinetobacter baumannii), for the determination of the minimum inhibitory concentration and bactericidal concentration. Among all the investigated Eos, the monoterpenes were highly present in the chemical composition. Moroccan, Saudi Arabian, and Syrian seeds were characterized by the presence $\alpha$-phellandrene (20.03-30.54\%), $\beta$-cymene (12.31-23.82 \%), and 4-caranol (9.77-14.27\%). The Indian seeds were rich with 4-caranol (18.81\%), $\beta$-cymene (14.22\%), $\alpha$-phellandrene (10.58\%), and $\beta$-chamigrene $(9.54 \%)$, while France NS was rich with estragole $(20.22 \%)$ and D-limonene $(14.63 \%)$. The minimum inhibitory (MIC) and bactericidal concentration (MBC) obtained for the four Eos (with the exception of France because of the low yield) tested were ranging from 3 to $40 \mu \mathrm{l} / \mathrm{ml}$. Gram-positive (+) bacteria were slightly sensitive to the Eos tested than the Gram-negative (-) bacteria. The results of this study showed that the Eos of NS seeds show interesting antibacterial activity which could be associated to the existence of different bioactive compounds. Indeed, these compounds can be used for preventive or curative purposes in the face of the noncontrolled emergence of resistance to antibiotics.
\end{abstract}

\section{Introduction}

Multidrug resistance to antibiotics has become a serious problem that threatens millions of people around the world. This resistance has led to an increase in research for new alternatives such as medicinal plants [1]. For this fact, the World Health Organization (WHO) has developed a list of global priority pathogens of multidrug-resistant bacteria to develop new effective antibiotic treatments [2].
Essential oils (Eos) are also named volatile compounds of the plant and known for their various benefits such as antibacterial, antifungal, and antiviral properties. The Eos are considered a major source in different domains such as perfumeries, cosmetics, and the pharmaceutical industry [3].

Nigella sativa L. (NS) (black cumin) annual herbaceous belonging to the Ranunculaceae family was largely used in folk medicine for centuries [4]. The plant is widely distributed in North Africa, the Middle East, and India. It is 
used for the treatment of various illnesses such as cough, asthma, fever, and eczema and for its benefit as a lactogogue and emmenagogue [5]. Nowadays, different biological studies are being established on NS; the richness of their seeds with volatile compounds, saponins, and alkaloids [6] provide a large spectrum of effects on different diseases [7]. Recently, it was proved that NS oil and extracts exert an antimicrobial, immunomodulatory, and anticancer activity [8].

The objective of this research is to study the chemical variation of the different NS Eos originated from India, Saudi Arabia, Morocco, Syria, and France and to evaluate their potential on some of the most common pathogenic multidrug-resistant bacteria: methicillin-resistant Staphylococcus aureus, Escherichia coli, Pseudomonas aeruginosa, and Acinetobacter baumannii isolated from the hospital.

\section{Materials and Methods}

\subsection{Materials}

2.1.1. Nigella sativa Seeds. The studied Nigella sativa seeds originate from five countries: Saudi Arabia, India, Syria, France, and Morocco. The determination of the scientific name of plant species was performed, verified, and confirmed with a taxonomist/professional botanist using live specimens and photographs. For the accuracy of the identification of plant species, we have referred to specialized documents related to Moroccan flora. A specimen was deposited at the faculty herbarium under the voucher number (HUMPOM471) [9-14].

2.1.2. Bacterial Strains. The bacteria used for the determination of the antibacterial activity (S.aureus, E.coli, P.aeruginosa, and A.baumannii) were clinically isolated from patients and identified at the microbiology laboratory of the University Hospital Centre Mohammed VI of Oujda (Morocco). Their sensitivity toward antibiotics was verified according to the European Committee on Antimicrobial Susceptibility Testing (EUCAST). The chosen strains are representative of the most commonly involved pathogenresistant bacteria in human infections.

2.1.3. Antimicrobial Susceptibility Testing. The in vitro antibiotic susceptibility test based on the disk diffusion method was used in this study. The isolated strains' sensitivity was accessed according to the EUCAST. The antibiotics tested and their concentrations are cefoxitin $30 \mu \mathrm{g}$ for methicillinresistant S. aureus, imipenem $10 \mu \mathrm{g}$ for Acinetobacter resistant to carbapenem, and ceftazidime $10 \mu \mathrm{g}$ for the ceftazidime-resistant Pseudomonas. For extended-spectrum beta-lactamases (ESBL), amoxicillin clavulanic acid $30 \mu \mathrm{g}$, cephalosporins third generation (Cefotaxime $5 \mu \mathrm{g}$ ) were used.

2.1.4. Chemicals. The following reagents and solvents were purchased from Sigma-Aldrich chemicals: hexane, dimethylsulfoxide (DMSO), and rizasurine sodium salt.
2.2. Essential Oil Extraction. The NS samples were placed in the shady room to be naturally dried until their weight was stable for (6 days) approximately. The fully dried samples were turned to a fine powder before hydrodistillation. Then, $100 \mathrm{~g}$ of plant material in $300 \mathrm{ml}$ of water were subjected to hydrodistillation using a modified Clevenger-type apparatus until the essential oil level was stable ( 2 to $3 \mathrm{~h}$ ). After the extraction, anhydrous sodium sulfate was used to remove water trace, and the essential oil was stored in an airtight glass container in a refrigerator at $4^{\circ} \mathrm{C}$ until the analysis.

\subsection{Qualitative and Semiquantitative Analysis of Nigella} sativa Essential Oil. The analysis was performed using a gas chromatograph (Shimadzu GC-2010) equipped with a fused-silica capillary column (5\% phenyl methyl siloxane, $30 \mathrm{~m} \times 0.25 \mathrm{~mm}, 0.25 \mu \mathrm{m}$ film thickness) coupled with a mass spectrometer detector (GC-MS-QP2010). The helium as a carrier gas was adjusted to a constant pressure of $100 \mathrm{KPa}$. The oven temperature was set initially at $50^{\circ} \mathrm{C}$ (maintained for 1 minute) followed by a gradient of $10^{\circ} \mathrm{C} /$ min up to $250^{\circ} \mathrm{C}$ (maintained for 1 minute). The temperatures of the injector, transfer line, and ion source were set at $250^{\circ} \mathrm{C}, 250^{\circ} \mathrm{C}$, and $200^{\circ} \mathrm{C}$, respectively. For the qualitative and semiqualitative analysis (Table 1 ), solutions containing $1 \mu \mathrm{L}$ of the samples diluted in hexane $(50 \mathrm{mg} / \mathrm{g})$ were injected in split mode (split ratio $=50-80$ ), and the GC-MS system was operated in scan mode. Mass spectra were recorded at $70 \mathrm{eV}$ (electron impact ionization mode) with an $\mathrm{m} / \mathrm{z}$ range of 40-350 a.m.u (rate and solvent delays were $5 \mathrm{~s} / \mathrm{scan}$ and 4.5 minutes, respectively). Identification of the essential oil constituents was accomplished based on the comparison of their MS data with those stored in the National Institute of Standards and Technology (NIST147) computer library. LabSolutions (version 2.5) was used for data collection and processing. Table 1 gives the relative percentage of each component of the studied Eos according to their GC peak areas without correction factors. All experiments were carried out in triplicate, and data was expressed as the mean \pm SD.

2.4. Determination of the Antibacterial Activity. The antibacterial activity of NS Eos has been determined using two different techniques as described below.

2.4.1. Agar Diffusion Method. The agar diffusion method was used as a preliminary test for the determination of the Eo antibacterial activity. The turbidity of all strains was standardized to 0.5 McFarland to facilitate the comparison between them. Afterward, the strains were inoculated on the surface of a Petri dish of Muller Hinton Agar (MHA) using a sterilized swab. Sterilized Whatman filters $(6 \mathrm{~mm}$ in diameter) were saturated with $20 \mu \mathrm{l}$ of Eo dissolved in $2 \%$ DMSO, and then, they were placed on the surface of the Petri dish previously inoculated with microorganisms using forceps. After 24 hours of incubation at $37^{\circ} \mathrm{C}$ of all the dishes, the antibacterial activity was assessed by measuring the diameter of the growth-inhibition zone in millimeter. The 
TABle 1: Chemical constituents identified in the Nigella sativa L. essential oils of five countries.

\begin{tabular}{|c|c|c|c|c|c|c|}
\hline Compounds & Retention time & India & Saudi Arabia & Morocco & Syria & France \\
\hline$\alpha$-Phellandrene & $4.97 \pm 0.00$ & $10.58 \pm 0.50$ & $30.54 \pm 1.01$ & $29.64 \pm 0.19$ & $20.03 \pm 0.56$ & $4.31 \pm 0.01$ \\
\hline$\alpha$-Pinene & $5.10 \pm 0.00$ & & & $6.29 \pm 0.04$ & $4.07 \pm 0.06$ & $1.07 \pm 0.01$ \\
\hline UC & $5.27 \pm 0.00$ & $0.12 \pm 0.01$ & $0.06 \pm 0.01$ & $0.13 \pm 0.00$ & $0.14 \pm 0.03$ & \\
\hline Camphene & $5.36 \pm 0.00$ & $0.15 \pm 0.02$ & $0.15 \pm 0.01$ & $0.12 \pm 0.03$ & $0.18 \pm 0.04$ & $0.19 \pm 0.03$ \\
\hline $\mathrm{UC}$ & $5.44 \pm 0.00$ & $0.05 \pm 0.02$ & \pm & $0.11 \pm 0.01$ & $0.11 \pm 0.06$ & $0.20 \pm 0.06$ \\
\hline UC & $5.67 \pm 0.00$ & & & & & $1.11 \pm 0.04$ \\
\hline$\beta$-Phellandrene & $5.74 \pm 0.00$ & $4.16 \pm 0.07$ & $4.42 \pm 0.12$ & $2.87 \pm 0.00$ & $2.39 \pm 0.03$ & $0.13 \pm 0.00$ \\
\hline$\beta$-Pinene & $5.82 \pm 0.00$ & $8.59 \pm 0.10$ & $9.77 \pm 0.33$ & $6.22 \pm 0.01$ & $4.53 \pm 0.07$ & $0.54 \pm 0.04$ \\
\hline$\beta$-Myrcene & $5.98 \pm 0.00$ & $0.17 \pm 0.03$ & $0.08 \pm 0.02$ & $0.15 \pm 0.02$ & $0.42 \pm 0.08$ & $0.42 \pm 0.00$ \\
\hline Ocimene & $6.02 \pm 0.00$ & & & & & $0.31 \pm 0.00$ \\
\hline UC & $6.04 \pm 0.01$ & $0.05 \pm 0.01$ & & & $0.33 \pm 0.01$ & \\
\hline Pseudocumol & $6.07 \pm 0.00$ & $0.11 \pm 0.01$ & $0.01 \pm 0.00$ & $0.32 \pm 0.01$ & $0.21 \pm 0.01$ & $0.50 \pm 0.01$ \\
\hline $\mathrm{UC}$ & $6.18 \pm 0.00$ & $0.07 \pm 0.04$ & $0.02 \pm 0.01$ & $0.05 \pm 0.00$ & $0.26 \pm 0.01$ & $0.21 \pm 0.00$ \\
\hline$\alpha$-Thujene & $6.24 \pm 0.00$ & $0.14 \pm 0.03$ & $0.07 \pm 0.03$ & $0.11 \pm 0.03$ & & \\
\hline$(+)$-4-Carene & $6.26 \pm 0.00$ & & & & $1.28 \pm 0.11$ & \\
\hline UC & $6.35 \pm 0.00$ & $0.10 \pm 0.03$ & $0.06 \pm 0.02$ & $0.20 \pm 0.04$ & & \\
\hline D-Limonene & $6.39 \pm 0.00$ & & & & & $14.63 \pm 1.42$ \\
\hline$\alpha$-Terpinen & $6.44 \pm 0.00$ & $1.67 \pm 0.09$ & $3.34 \pm 0.17$ & $2.25 \pm 0.00$ & & \\
\hline $\mathrm{UC}^{1}$ & $6.45 \pm 0.00$ & & & & & $1.41 \pm 0.29$ \\
\hline UC & $6.51 \pm 0.00$ & $0.06 \pm 0.01$ & $0.07 \pm 0.01$ & \pm & & \pm \\
\hline$\beta$-Cymene & $6.56 \pm 0.01$ & $14.22 \pm 0.08$ & $12.31 \pm 0.67$ & $23.82 \pm 0.04$ & $14.61 \pm 1.27$ & $0.29 \pm 0.00$ \\
\hline $\mathrm{UC}$ & $6.60 \pm 0.00$ & & & & $0.27 \pm 0.02$ & $0.19 \pm 0.01$ \\
\hline UC & $6.71 \pm 0.00$ & & & & $0.23 \pm 0.01$ & \\
\hline UC & $6.77 \pm 0.00$ & & & & $0.39 \pm 0.05$ & \\
\hline Thujol & $6.98 \pm 0.00$ & $0.05 \pm 0.00$ & $0.02 \pm 0.00$ & $0.02 \pm 0.01$ & $0.73 \pm 0.10$ & $0.63 \pm 0.12$ \\
\hline$\gamma$-Terpinene & $7.14 \pm 0.00$ & $6.38 \pm 0.34$ & $1.89 \pm 0.10$ & $1.25 \pm 0.06$ & $5.77 \pm 0.11$ & $0.18 \pm 0.07$ \\
\hline $\mathrm{UC}$ & $7.24 \pm 0.00$ & & & & $0.44 \pm 0.06$ & \\
\hline cis- $\beta$-Terpineol & $7.29 \pm 0.00$ & $0.18 \pm 0.01$ & $0.17 \pm 0.02$ & $0.11 \pm 0.01$ & $0.48 \pm 0.08$ & $0.96 \pm 0.12$ \\
\hline Terpinolen & $7.64 \pm 0.00$ & $0.37 \pm 0.02$ & $0.25 \pm 0.03$ & $0.15 \pm 0.02$ & $63 \pm 0.08$ & $0.58 \pm 0.13$ \\
\hline $\mathrm{UC}$ & $7.68 \pm 0.00$ & & & & $0.25 \pm 0.02$ & \\
\hline 3-Caranol & $7.76 \pm 0.00$ & & & & $0.28 \pm 0.04$ & $0.20 \pm 0.06$ \\
\hline Neodihydrocarveol & $7.77 \pm 0.00$ & $3.34 \pm 0.19$ & $2.51 \pm 0.03$ & $1.63 \pm 0.00$ & $3.50 \pm 0.25$ & $0.52 \pm 0.01$ \\
\hline UC & $8.04 \pm 0.00$ & $0.04 \pm 0.01$ & $0.04 \pm 0.01$ & $0.04 \pm 0.01$ & $0.31 \pm 0.00$ & \\
\hline 4-Caranol & $8.14 \pm 0.00$ & $18.81 \pm 0.57$ & $14.27 \pm 0.11$ & $9.77 \pm 0.08$ & $9.85 \pm 0.65$ & $2.05 \pm 0.03$ \\
\hline $\mathrm{UC}$ & $8.29 \pm 0.00$ & $0.07 \pm 0.03$ & $0.05 \pm 0.00$ & $0.03 \pm 0.01$ & $0.35 \pm 0.03$ & $0.49 \pm 0.01$ \\
\hline UC & $8.45 \pm 0.00$ & $0.27 \pm 0.01$ & $0.43 \pm 0.04$ & $0.25 \pm 0.03$ & $0.46 \pm 0.00$ & $0.22 \pm 0.03$ \\
\hline $\mathrm{UC}$ & $8.57 \pm 0.00$ & $0.04 \pm 0.00$ & $0.02 \pm 0.00$ & $0.01 \pm 0.01$ & $0.36 \pm 0.07$ & $0.47 \pm 0.03$ \\
\hline Limonene oxide & $8.57 \pm 0.00$ & & & & $0.66 \pm 0.09$ & $0.29 \pm 0.07$ \\
\hline Camphor & $8.62 \pm 0.00$ & $0.08 \pm 0.01$ & $0.07 \pm 0.02$ & $0.05 \pm 0.00$ & $0.27 \pm 0.04$ & $0.96 \pm 0.14$ \\
\hline$\beta$-Cyclocitral & $8.75 \pm 0.00$ & $0.12 \pm 0.02$ & $0.05 \pm 0.01$ & $0.03 \pm 0.00$ & $0.17 \pm 0.01$ & $0.24 \pm 0.10$ \\
\hline UC & $8.77 \pm 0.00$ & & & & & $0.94 \pm 0.18$ \\
\hline p-Cymen-8-ol & $8.87 \pm 0.00$ & & & & $0.24 \pm 0.02$ & $0.18 \pm 0.01$ \\
\hline Limonene epoxide & $8.89 \pm 0.00$ & $1.02 \pm 0.07$ & $0.78 \pm 0.01$ & $0.52 \pm 0.01$ & $0.42 \pm 0.04$ & $0.45 \pm 0.07$ \\
\hline $\mathrm{UC}$ & $8.99 \pm 0.00$ & $0.11 \pm 0.00$ & $0.04 \pm 0.01$ & $0.03 \pm 0.01$ & $0.40 \pm 0.02$ & $0.16 \pm 0.02$ \\
\hline 4-Carvomenthenol & $9.10 \pm 0.00$ & $3.35 \pm 0.03$ & $2.11 \pm 0.01$ & $1.44 \pm 0.06$ & $1.67 \pm 0.03$ & $0.47 \pm 0.13$ \\
\hline $\mathrm{UC}$ & $9.19 \pm 0.00$ & $0.24 \pm 0.02$ & $0.20 \pm 0.00$ & $0.15 \pm 0.01$ & $0.12 \pm 0.03$ & \\
\hline $\mathrm{UC}$ & $9.25 \pm 0.00$ & $0.03 \pm 0.00$ & $0.02 \pm 0.00$ & $0.01 \pm 0.00$ & $0.32 \pm 0.07$ & $0.82 \pm 0.04$ \\
\hline UC & $9.30 \pm 0.00$ & $0.11 \pm 0.01$ & $0.04 \pm 0.00$ & $0.03 \pm 0.00$ & $0.33 \pm 0.03$ & \\
\hline $\mathrm{UC}$ & $9.40 \pm 0.00$ & $0.10 \pm 0.01$ & $0.08 \pm 0.03$ & $0.07 \pm 0.01$ & & $0.39 \pm 0.02$ \\
\hline$\beta$-Cyclocitral & $9.50 \pm 0.00$ & $2.10 \pm 0.13$ & $2.0 \pm 0.05$ & $1.39 \pm 0.02$ & $1.06 \pm 0.01$ & $0.24 \pm 0.01$ \\
\hline $\mathrm{UC}$ & $9.54 \pm 0.00$ & & & & $0.19 \pm 0.01$ & $0.24 \pm 0.07$ \\
\hline UC & $9.55 \pm 0.00$ & $0.04 \pm 0.00$ & & $0.02 \pm 0.01$ & $0.46 \pm 0.02$ & $0.22 \pm 0.05$ \\
\hline $\mathrm{UC}$ & $9.74 \pm 0.00$ & $0.34 \pm 0.04$ & $0.13 \pm 0.00$ & $0.08 \pm 0.00$ & $0.35 \pm 0.02$ & $0.15 \pm 0.01$ \\
\hline Solanone & $9.98 \pm 0.00$ & & & & $0.42 \pm 0.02$ & $0.51 \pm 0.03$ \\
\hline Cuminal & $10.08 \pm 0.00$ & $0.09 \pm 0.01$ & $0.24 \pm 0.06$ & $0.13 \pm 0.02$ & $0.19 \pm 0.02$ & $0.51 \pm 0.03$ \\
\hline Carvone & $10.14 \pm 0.00$ & $0.18 \pm 0.01$ & $0.24 \pm 0.01$ & $0.010 .15 \pm 0.04$ & $0.23 \pm 0.01$ & $1.01 \pm 0.12$ \\
\hline cis-Verbenol & $10.19 \pm 0.00$ & & & & $0.17 \pm 0.03$ & $0.40 \pm 0.00$ \\
\hline Thymoquinon & $10.21 \pm 0.00$ & $0.32 \pm 0.03$ & $0.70 \pm 0.10$ & $0.50 \pm 0.06$ & $0.82 \pm 0.11$ & \\
\hline $\mathrm{UC}$ & $10.25 \pm 0.00$ & & & & $0.08 \pm 0.01$ & \\
\hline cis-Verbenol & $10.27 \pm 0.00$ & $0.12 \pm 0.01$ & $0.08 \pm 0.00$ & $0.05 \pm 0.01$ & $0.19 \pm 0.00$ & $0.96 \pm 0.01$ \\
\hline
\end{tabular}


TABle 1: Continued.

\begin{tabular}{|c|c|c|c|c|c|c|}
\hline Compounds & Retention time & India & Saudi Arabia & Morocco & Syria & France \\
\hline $\mathrm{UC}$ & $10.31 \pm 0.00$ & $0.02 \pm 0.01$ & & & & $0.63 \pm 0.14$ \\
\hline Estragole & $10.32 \pm 0.00$ & & & & & $20.22 \pm 0.59$ \\
\hline 4-Carene & $10.38 \pm 0.00$ & $0.24 \pm 0.02$ & $0.13 \pm 0.01$ & $0.09 \pm 0.01$ & $0.33 \pm 0.08$ & $0.64 \pm 0.04$ \\
\hline Carvacrol & $10.49 \pm 0.00$ & & & & $2.30 \pm 0.09$ & $1.22 \pm 0.07$ \\
\hline UC & $10.71 \pm 0.00$ & & & & $0.18 \pm 0.04$ & $0.28 \pm 0.04$ \\
\hline Bornyl acetate & $10.76 \pm 0.00$ & $1.14 \pm 0.09$ & $0.84 \pm 0.05$ & $0.59 \pm 0.05$ & $1.18 \pm 0.04$ & \\
\hline UC & $10.86 \pm 0.00$ & $0.09 \pm 0.01$ & $0.03 \pm 0.00$ & \pm & $0.12 \pm 0.01$ & \\
\hline Thymol & $10.92 \pm 0.00$ & $4.64 \pm 0.01$ & $8.39 \pm 0.39$ & $7.00 \pm 0.03$ & \pm & \\
\hline UC & $11.14 \pm 0.00$ & $0.07 \pm 0.03$ & $0.02 \pm 0.00$ & $0.04 \pm 0.00$ & $0.18 \pm 0.03$ & \\
\hline UC & $11.30 \pm 0.00$ & $0.04 \pm 0.01$ & $0.02 \pm 0.01$ & & & \\
\hline $\mathrm{UC}$ & $11.55 \pm 0.00$ & & & & $0.20 \pm 0.01$ & \\
\hline Cedrene & $11.60 \pm 0.00$ & & & & & $0.22 \pm 0.01$ \\
\hline$\beta$-Terpinyl acetate & $11.65 \pm 0.00$ & $0.10 \pm 0.03$ & $0.02 \pm 0.00$ & $0.18 \pm 0.02$ & & \pm \\
\hline$\alpha$-Longipinene & $11.78 \pm 0.00$ & $2.23 \pm 0.09$ & $0.29 \pm 0.02$ & $0.18 \pm 0.01$ & $1.22 \pm 0.05$ & $0.51 \pm 0.10$ \\
\hline $\mathrm{UC}$ & $12.05 \pm 0.00$ & $0.06 \pm 0.02$ & & & $0.15 \pm 0.03$ & \\
\hline Patchoulene & $12.07 \pm 0.00$ & & & & $4.00 \pm 0.05$ & $3.29 \pm 0.00$ \\
\hline Columbin & $12.11 \pm 0.00$ & $0.14 \pm 0.02$ & $0.05 \pm 0.01$ & $0.02 \pm 0.00$ & & \\
\hline $\mathrm{UC}$ & $12.16 \pm 0.00$ & $0.04 \pm 0.01$ & $0.02 \pm 0.00$ & & $0.12 \pm 0.04$ & $0.42 \pm 0.00$ \\
\hline Aromadendrene & $12.22 \pm 0.00$ & & & & $0.29 \pm 0.04$ & $0.69 \pm 0.10$ \\
\hline UC & $12.31 \pm 0.00$ & $0.04 \pm 0.01$ & $0.02 \pm 0.01$ & $0.01 \pm 0.00$ & $0.18 \pm 0.01$ & $0.19 \pm 0.05$ \\
\hline UC & $12.41 \pm 0.00$ & $0.06 \pm 0.01$ & $0.02 \pm 0.00$ & $0.04 \pm 0.02$ & $0.18 \pm 0.00$ & $0.24 \pm 0.01$ \\
\hline UC & $12.51 \pm 0.00$ & $0.06 \pm 0.02$ & & & & \\
\hline Longicyclene & $12.56 \pm 0.00$ & $0.31 \pm 0.02$ & $0.02 \pm 0.00$ & \pm & 0.00 & \\
\hline$\beta$-Chamigrene & $12.62 \pm 0.00$ & $9.54 \pm 0.49$ & $1.54 \pm 0.08$ & $1.14 \pm 0.02$ & & \\
\hline UC & $12.68 \pm 0.00$ & $0.02 \pm 0.01$ & & & $0.13 \pm 0.03$ & $0.19 \pm 0.03$ \\
\hline$\alpha$-Bisabolene & $12.77 \pm 0.00$ & $0.18 \pm 0.02$ & $0.06 \pm 0.01$ & $0.03 \pm 0.01$ & $0.21 \pm 0.04$ & $0.62 \pm 0.00$ \\
\hline Longifolene-(V4) & $12.91 \pm 0.00$ & & & & & $2.61 \pm 0.02$ \\
\hline $\mathrm{UC}$ & $12.99 \pm 0.00$ & & & & & $1.20 \pm 0.07$ \\
\hline UC & $13.00 \pm 0.00$ & $0.05 \pm 0.01$ & $0.04 \pm 0.02$ & $0.01 \pm 0.00$ & $0.25 \pm 0.02$ & $0.20 \pm 0.09$ \\
\hline Methyl undecyl ketone & $13.07 \pm 0.00$ & & & & $1.51 \pm 0.11$ & $0.79 \pm 0.04$ \\
\hline UC & $13.12 \pm 0.01$ & $0.03 \pm 0.01$ & $0.04 \pm 0.01$ & $0.01 \pm 0.00$ & $0.75 \pm 0.09$ & \\
\hline UC & $13.17 \pm 0.00$ & & & & $0.87 \pm 0.07$ & $0.47 \pm 0.07$ \\
\hline a-Curcumene & $13.28 \pm 0.00$ & $0.11 \pm 0.03$ & $0.03 \pm 0.00$ & $0.02 \pm 0.00$ & & $0.25 \pm 0.02$ \\
\hline b-Sesquiphellandrene & $13.38 \pm 0.00$ & & & & & $0.36 \pm 0.01$ \\
\hline $\mathrm{UC}$ & $13.49 \pm 0.00$ & $0.06 \pm 0.01$ & $0.05 \pm 0.01$ & $0.03 \pm 0.02$ & $0.32 \pm 0.08$ & \\
\hline 2-Tridecanone & $13.57 \pm 0.00$ & $0.38 \pm 0.02$ & $0.11 \pm 0.02$ & $0.07 \pm 0.02$ & $1.13 \pm 0.03$ & $1.40 \pm 0.14$ \\
\hline $\mathrm{UC}$ & $13.64 \pm 0.00$ & $0.07 \pm 0.02$ & $0.04 \pm 0.01$ & $0.02 \pm 0.01$ & $0.19 \pm 0.02$ & $1.14 \pm 0.04$ \\
\hline$\beta$-Bisabolene & $13.83 \pm 0.00$ & $0.17 \pm 0.03$ & $0.04 \pm 0.01$ & $0.03 \pm 0.01$ & $0.14 \pm 0.08$ & $0.15 \pm 0.01$ \\
\hline $\mathrm{UC}$ & $13.99 \pm 0.00$ & $0.06 \pm 0.01$ & $0.04 \pm 0.01$ & $0.02 \pm 0.00$ & \pm & $0.23 \pm 0.07$ \\
\hline Isoledene & $14.15 \pm 0.00$ & $0.15 \pm 0.02$ & $0.03 \pm 0.01$ & $0.01 \pm 0.01$ & $0.16 \pm 0.01$ & $0.37 \pm 0.04$ \\
\hline UC & $14.40 \pm 0.00$ & $0.04 \pm 0.00$ & $0.04 \pm 0.01$ & $0.02 \pm 0.01$ & $0.15 \pm 0.04$ & $0.92 \pm 0.13$ \\
\hline UC & $14.72 \pm 0.00$ & $0.04 \pm 0.01$ & & $0.02 \pm 0.00$ & $0.13 \pm 0.03$ & $0.79 \pm 0.06$ \\
\hline a-Pentylcinnamaldehyde & $14.78 \pm 0.00$ & & & & & $0.47 \pm 0.08$ \\
\hline $\mathrm{UC}$ & $14.85 \pm 0.00$ & $0.28 \pm 0.03$ & $0.13 \pm 0.03$ & $0.07 \pm 0.02$ & $0.15 \pm 0.06$ & $1.21 \pm 0.03$ \\
\hline Ar-tumerone & $15.05 \pm 0.00$ & \pm & \pm & \pm & \pm & $0.55 \pm 0.04$ \\
\hline UC & $15.06 \pm 0.00$ & $0.22 \pm 0.03$ & $0.10 \pm 0.01$ & $0.06 \pm 0.00$ & $0.24 \pm 0.02$ & $0.38 \pm 0.10$ \\
\hline UC & $15.17 \pm 0.00$ & $0.07 \pm 0.01$ & $0.02 \pm 0.01$ & $0.05 \pm 0.05$ & $0.18 \pm 0.06$ & $1.30 \pm 0.14$ \\
\hline Curlone & $15.41 \pm 0.00$ & & & & & $0.67 \pm 0.06$ \\
\hline UC & $15.62 \pm 0.00$ & $0.09 \pm 0.02$ & $0.05 \pm 0.01$ & $0.01 \pm 0.00$ & $0.21 \pm 0.10$ & $2.38 \pm 0.01$ \\
\hline $\mathrm{UC}$ & $15.87 \pm 0.00$ & $0.15 \pm 0.03$ & $0.06 \pm 0.02$ & $0.05 \pm 0.02$ & & $1.09 \pm 0.04$ \\
\hline $\mathrm{UC}$ & $16.04 \pm 0.00$ & $0.09 \pm 0.02$ & & $0.02 \pm 0.01$ & & \\
\hline $\mathrm{UC}$ & $16.09 \pm 0.00$ & $0.11 \pm 0.02$ & $0.05 \pm 0.01$ & & & \\
\hline Globulol & $16.15 \pm 0.00$ & $0.34 \pm 0.04$ & $0.05 \pm 0.00$ & $0.03 \pm 0.01$ & $0.13 \pm 0.04$ & $1.42 \pm 0.00$ \\
\hline Palmitic acid & $16.55 \pm 0.00$ & & & & & $0.16 \pm 0.01$ \\
\hline $\mathrm{UC}$ & $16.64 \pm 0.00$ & $0.21 \pm .05$ & $0.15 \pm 0.03$ & $0.06 \pm 0.02$ & $0.27 \pm 0.03$ & $2.09 \pm 0.00$ \\
\hline $\mathrm{UC}$ & $16.88 \pm 0.00$ & $0.09 \pm 0.02$ & $0.03 \pm 0.01$ & $0.02 \pm 0.00$ & $0.23 \pm 0.08$ & \\
\hline Biformene & $18.18 \pm 0.02$ & & & & & $1.07 \pm 0.05$ \\
\hline $\mathrm{UC}$ & $18.24 \pm 0.00$ & & & & & $4.16 \pm 0.17$ \\
\hline UC & $18.34 \pm 0.01$ & & & & & $1.85 \pm 0.06$ \\
\hline 7,10-Octadecadienoic acid & $19.21 \pm 0.01$ & & & & & $0.55 \pm 0.04$ \\
\hline UC & $19.39 \pm 0.00$ & & & & & $2.97 \pm 0.03$ \\
\hline
\end{tabular}


measurements of inhibition zones were carried out three times for each Eo [15].

2.4.2. Determination of Minimal Inhibitory (MIC) and Bactericidal $(M B C)$ Concentrations. In this study, the microdilution method using a 96-well plate was adopted. Resazurin was utilized as an indicator of bacterial growth for the determination of MIC [16]. Resazurin is a nonfluorescent purple/blue dye that becomes pink and fluorescent when reduced to resorufin by oxidoreductase enzymes in viable cells [17].

The essential oil was dissolved in 2\% DMSO, and a serial dilution was prepared in Muller Hinton broth. After the stirring, $180 \mu \mathrm{l}$ of each concentration was added to the plate wells. Then, a suspension of bacteria cells $\left(10^{7} \mathrm{CFU} / \mathrm{ml}\right.$, $20 \mu \mathrm{l})$ was added to each well. After adding resazurin, all the plates were incubated at $37^{\circ} \mathrm{C}$ for $24 \mathrm{~h}$. The smallest concentration of essential oil that shows no color variation was considered as the MIC.

Afterward, $20 \mu \mathrm{l}$ is withdrawn from each well of the microplate, which does not show any color change, spread on the surface of the MHA Petri dish using a sterilized swab, and then, incubated at $37^{\circ} \mathrm{C}$ for 18 to 24 hours. The dish with no subculture was considered as the MBC.

All tests were performed in triplicates including the antibiotic MHB as a positive control and essential oil dissolved in DMSO 2\% without the microorganism as a negative control.

2.5. Statistical Analysis. The analysis was performed with ANOVA followed by the Tukey test with post hoc multiple comparisons threshold 5\%. The oil components with a percentage higher than $5 \%$ of the total oil were subjected to hierarchical cluster analysis (HCA) and principal component analysis (PCA) using SPSS v22.0 software. In the case of HCA, the dendrogram (tree) was produced using Ward's method of hierarchical clustering with the squared Euclidean distance between oil samples.

\section{Results and Discussion}

3.1. Extraction and Chemical Composition of Essential Oils. The essential oils (Eos) of five NS samples belonging to five countries (India, Saudi Arabia, Morocco, Syria, and France) were obtained by the hydrodistillation method in a yield ranging from $0.047 \%$ to $1.7 \%$. The composition of the Eos was investigated using the GC-MS technique, and the identification of their constituents was accomplished based on the comparison of their MS data with those stored in the National Institute of Standards and Technology (NIST147) computer library. The chemical components and the chromatograms of the studied oils are shown in Table 1 and Figure 1, respectively. Of all of the identified compounds, monoterpenes constituted the highest percentage (55.81 to $96.68 \%)$. The data show that the major components were found to be $\alpha$-phellandrene, $\beta$-pinene, $\beta$-cymene, and 4 caranol, respectively, for NS collected from India, Saudi Arabia, Morocco, and Syria. Oil compositions of France were characterized by the occurrence, at appreciable content, of estragole and D-limonene.

3.2. Chemical Variation in Essential Oil Composition. The oil components with percentages higher than or equal $5 \%$ of the total oil were subjected to hierarchical cluster (HCA) and principal component analysis (PCA) in order to investigate the similarity and relationship between Eos composition of NS samples.

From a dendrogram produced by HCA (Figure 2), the $N S$ populations can be classified into two main clusters at a distance of 25 units. Samples connected by a shorter distance are more similar than those connected by a longer distance. In the closer distances ( $\sim 5$ units), the examined populations were divided into three groups ( $\mathrm{Gr} 1$ to 3 ). The first group (cluster I), represented by three samples originating from Saudi Arabia, Morocco, and Syria, was rich in $\alpha$-phellandrene $(20.03-30.54 \%)$ and had a relatively moderate level of $\beta$-cymene (12.31-23.82 \%) and 4-caranol (9.77-14.27\%). The second group, containing the sample of India and which is furthest from the other populations of cluster I, is characterized by the highest percentage of $\beta$-chamigrene (9.54\%).

In the third group (cluster II), the France sample which constitutes the furthest group compared to the others had high and moderate levels in estragole (20.22\%) and D-limonene $(14.63 \%)$ respectively.

PCA analysis revealed that the first two principal components represented $82 \%$ of the phytochemical variance. Figure 3 shows the 2D graphical representation of PCA. As shown in the figure, the first principal component (PC1) accounted for $57 \%$ of the total variance, correlated positively with $\alpha$-phellandrene, $\beta$-pinene, $\beta$-cymene, and 4 -caranol which were predominant in oils of NS collected from Saudi Arabia, Morocco, Syria, and India. On the other hand, PC1 correlated negatively with $\mathrm{D}$-limonene and estragole which were predominant in oils of NS originated from France. The second principal component, accounting for an additional $25 \%$ of the total variance, was positively correlated with $\beta$-chamigrene. These PCA data lead to the classification of the NS into three main groups which represent the following chemotypes: $\alpha$-phellandrene/ $\beta$-cymene/4-caranol (Saudi Arabia, Morocco, and Syria), 4 -caranol $/ \beta$-cymene $/ \alpha$-phellandrene/ $\beta$-chamigrene (India), and estragole/D-limonene (France). This classification confirmed the HCA results.

Finally, it is interesting to note the great similarity between Eos of NS samples collected from India, Saudi Arabia, Morocco, and Syria despite that they grew under different edaphic and climatic conditions. Such a close similarity of oil composition in plants can be explained by the similarity of the genetic factors.

3.3. Determination of the Antibacterial Activity. The sensitivity test showed that the different strains were resistant towards the used antibiotics, and no inhibition diameter was observed on the agar plate. Concerning the ESBL, the double-disc synergy method in Mueller Hinton agar was used. The amoxicillin clavulanic acid inhibits the production of beta-lactamases which create a synergic effect with 


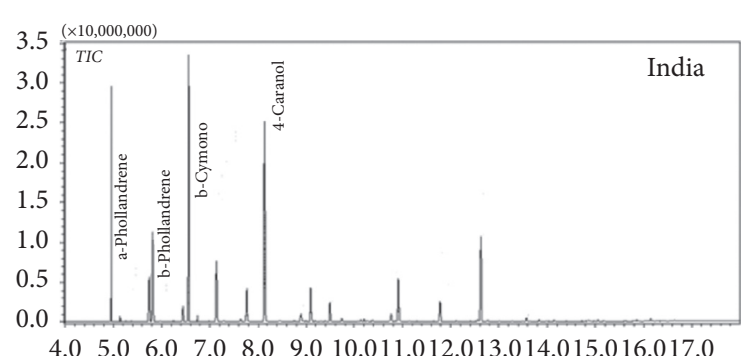

(a)

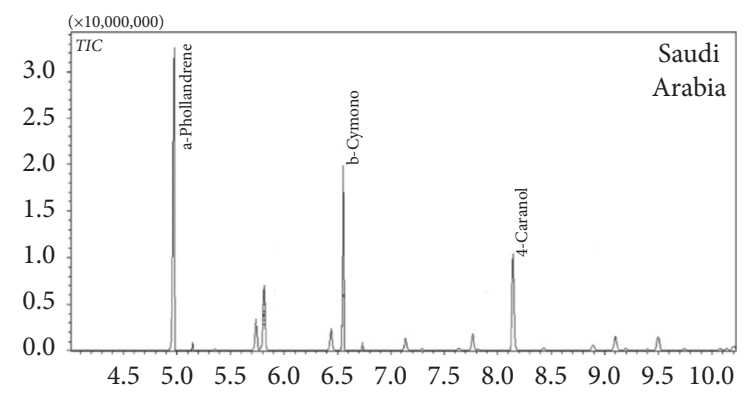

(c)

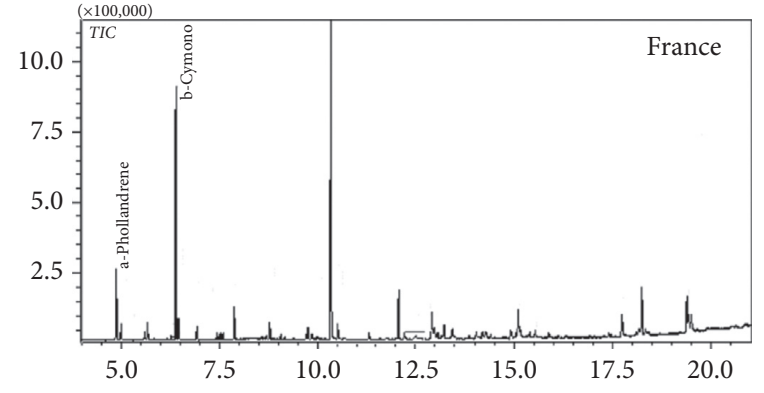

(b)

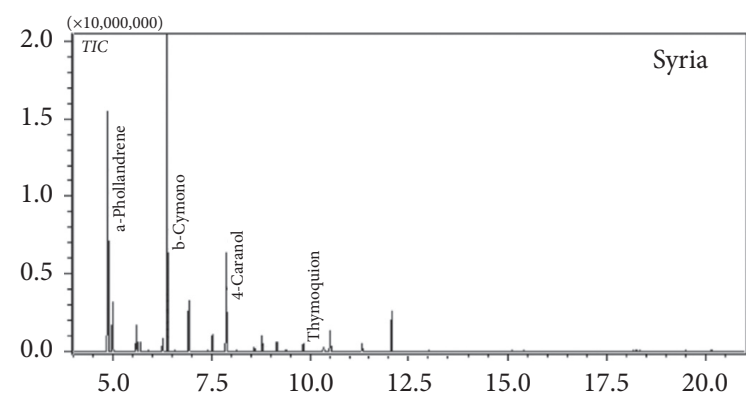

(d)

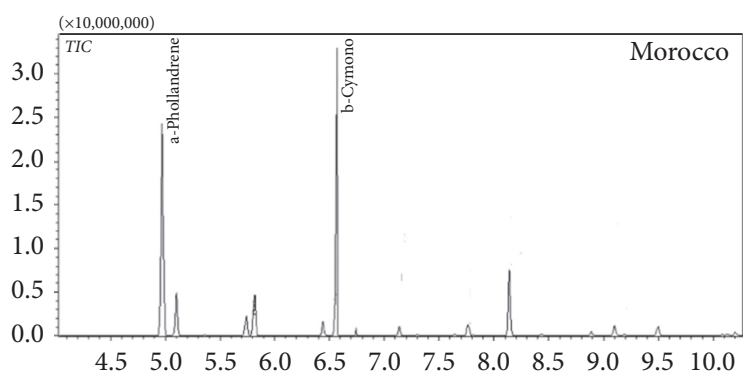

(e)

Figure 1: GC-MS Total Ion Chromatogram (TIC) of the Nigella sativa essential oils of five countries.

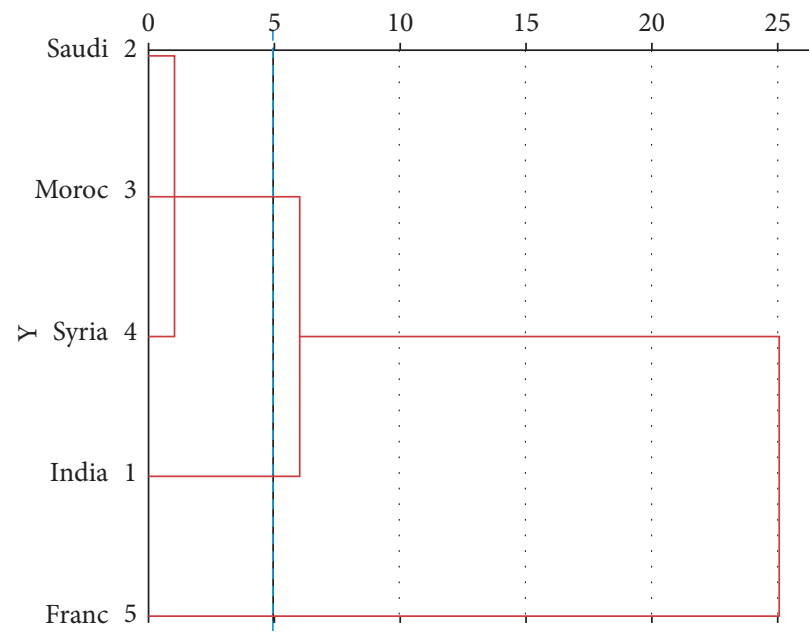

FIGURE 2: Dendrogram of five Nigella sativa populations produced by the hierarchical cluster analysis. 


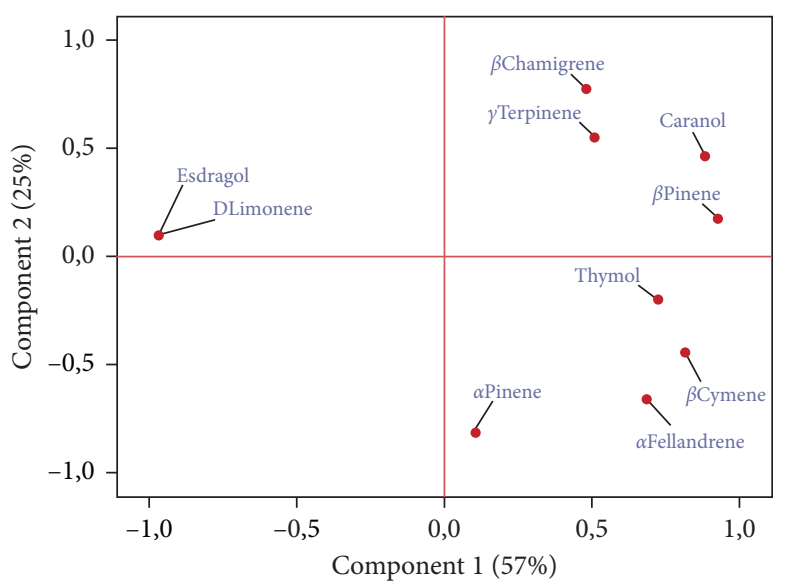

(a)

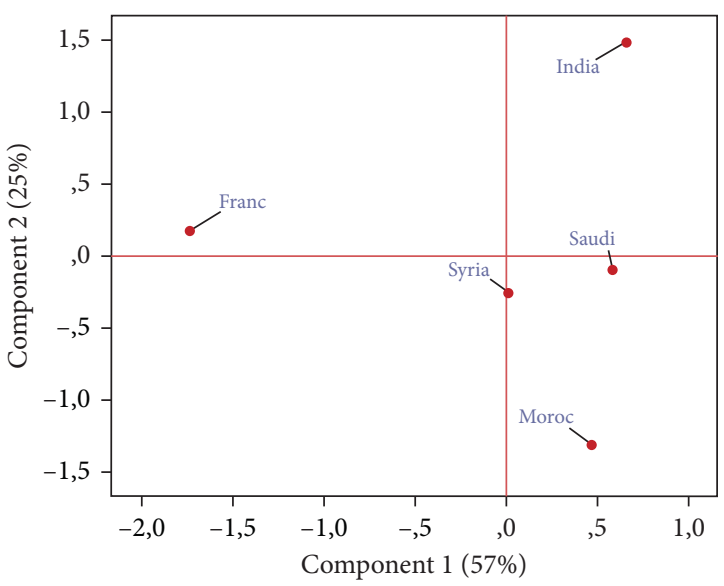

(b)

FIGURE 3: 2D graphical representation of principal component analysis of chemical compositions oils of NS originated from five countries. (a, b) PCA distributions of variables and samples, respectively.

cephalosporins third generation which highly suggest the production of ESBL.

NS Eos were evaluated for their antimicrobial activity against four bacteria-resistant strains: S. aureus, E. coli, $P$. aeruginosa, and $A$. baumannii. The data pertaining to the antimicrobial potential of NS Eos are presented in Table 2.

Among the tested bacteria, the multiresistant $S$. aureus (MRSA) was considered as sensitive to all Eos tested (zone inhibition: 14 to $15 \mathrm{~mm}$ ) except for the Saudi Arabian Eo which gave a moderately sensitive activity $(10 \mathrm{~mm})$. As depicted in the same table, A. baumannii (12.5 to $13.5 \mathrm{~mm})$ and $P$. aeruginosa (10.06 to $12.5 \mathrm{~mm}$ ) were deemed as moderately sensitive to all origins of Eos. Based on the zone inhibition ( 8 to $9.5 \mathrm{~mm}$ ), the E. coli was regarded as slightly sensitive to the volatile compounds of the four countries. The comparison of the inhibition activity according to the origin was not significant $(p>0.05)$, while the comparison between all strains tested is very highly significant $(p<0.001)$.

The MICs were measured using the microdilution method on 96-well plates, and the results obtained were recorded in Table 3.

All results reflect that the Eos from the different origins present an important inhibitory activity on all tested bacteria. The MRSA was the most sensitive bacterial strain to all Eos. The MICs recorded for the four origins were ranging from 3 to $10 \mu \mathrm{l} / \mathrm{ml}$ with a slight difference with those observed in $\mathrm{MBC}$ values.

Regarding A. baumannii and E. coli, all MICs values were equal to those of MBCs (10 to $20 \mu \mathrm{l} / \mathrm{ml}$ ). As for P. aeruginosa, there was a difference between the MIC of India $(10 \mu \mathrm{l} / \mathrm{ml})$ and MICs of Syria, Saudi Arabia, and Morocco $(20 \mu \mathrm{l} / \mathrm{ml})$, but the MBCs values were the same for India, Morocco, and Saudi Arabia $(30 \mu \mathrm{l} / \mathrm{ml})$ with an increase in the MBC of Syria Eo $(40 \mu \mathrm{l} / \mathrm{ml})$.

\section{Discussion}

Regarding the chemical profile, the results obtained in our study displayed a different chemical profile with the literature when
TABLE 2: Zone of inhibition means ( $\mathrm{mm}$ ) of Nigella sativa essential oils (Eos) for tested bacterial strains.

\begin{tabular}{lcccc}
\hline \multirow{2}{*}{ Origins } & \multicolumn{4}{c}{ Bacterial strains } \\
& MRSA & A. baumannii & E. coli & P. aeruginosa \\
\hline India & $15,1 \pm 0,13$ & $12,5 \pm 0$ & $8 \pm 0,28$ & $12,03 \pm 0,11$ \\
Saudi & $10 \pm 0,25$ & $13,5 \pm 0,22$ & $8,5 \pm 0,09$ & $11,5 \pm 0,21$ \\
Arabia & & $13 \pm 0,02$ & $9,5 \pm 0,33$ & $12,5 \pm 0,16$ \\
Morocco & $14 \pm 0,33$ & $13 \pm 0,27$ & $9 \pm 0,13$ & $10,06 \pm 0,09$ \\
Syria & $15 \pm 0,67$ & 13 &
\end{tabular}

compared with the NS Eos from Iran, Tunisia, and Algeria [18-20], which confirms that the composition of the Eos is highly influenced by climatic conditions and also by the difference of the geographical location as mentioned in [21].

It is widely known that the volatile compounds are endowed with a great capacity to interrupt the production of energy on the mitochondrial membrane by damaging the proton pump; also, these compounds have the ability to inhibit the synthesis of structural macromolecules and growth regulators [22,23].

The antibacterial activity of NS volatile compounds for the studied countries (India, Saudi Arabia, Morocco, and Syria) could be associated to the different molecules identified with the GC-MS such as $\alpha$-phellandrene, $\beta$-cymene, $\beta$-pinene, and thymol.

The obtained results indicate that the Eos originated from the four countries studied exert an antibacterial activity that was more potent in Gram-positive than the Gramnegative bacteria, and this could be due to the presence of an intrinsic system of resistance to Eos. Man et al. [24] indicated that the reaction of bacteria depends mainly on their morphology (bacterial wall), the peptidoglycan present on the Gram-positive bacterial wall allows the hydrophobic molecules to reach the internal environment, while the lipopolysaccharide present on the Gram-negative bacteria enables the passage of small hydrophilic molecules which are not affected by the resistance, and this is due to the abundance of porin proteins [25]. 
TABLe 3: The MIC and MBC in $\mu \mathrm{l} / \mathrm{ml}$ of Nigella sativa essential oils against tested bacteria.

\begin{tabular}{|c|c|c|c|c|c|c|c|c|}
\hline \multirow{3}{*}{ Origins } & \multicolumn{8}{|c|}{ Bacterial strains } \\
\hline & \multicolumn{2}{|c|}{$M R S A$} & \multicolumn{2}{|c|}{ A. baumannii } & \multicolumn{2}{|c|}{ E. coli } & \multicolumn{2}{|c|}{ P. aeruginosa } \\
\hline & MIC & $\mathrm{MBC}$ & MIC & $\mathrm{MBC}$ & MIC & $\mathrm{MBC}$ & MIC & $\mathrm{MBC}$ \\
\hline India & 10 & 10 & 20 & 20 & 20 & 20 & 10 & 30 \\
\hline Saudi Arabia & 3 & 5 & 20 & 20 & 20 & 20 & 20 & 30 \\
\hline Morocco & 5 & 10 & 20 & 20 & 20 & 20 & 20 & 30 \\
\hline Syria & 3 & 3 & 10 & 10 & 20 & 20 & 20 & 40 \\
\hline
\end{tabular}

$\mathrm{MIC}$ and $\mathrm{MBC}$ are minimal inhibitory concentration and minimal bactericidal concentration, respectively.

Concerning the antibacterial effect, it was reported that Tunisian NS Eos have shown an antibacterial activity against two strains the E.coli $\left(\mathrm{IC}_{50} 62.0 \mu \mathrm{g} / \mathrm{ml}\right)$ and $S$. aureus $\left(\mathrm{IC}_{50}\right.$ $12.0 \mu \mathrm{g} / \mathrm{ml}$ ); also, they suggested that these effects could be attributed to thymoquinone and longifolene [18].

In another study, the Eos showed an important activity on different multiresistant Gram-positive and Gramnegative strains, but no effect was observed on A. baumannii, which is contradictory to our results where all Eos studied have shown an inhibition of bacteria with an MIC value ranging from 10 to $20 \mu \mathrm{l} / \mathrm{ml}$ [26], while in Deloer and Bari's study [27], the Eo had an important activity with low concentration on various strains with the exception of E. coli where the Eos were not active in all tested concentrations which was different from our findings where the Eos were active on E. coli with a MIC $(20 \mu \mathrm{l} / \mathrm{ml})$. The Eos in Singh et al.'s [28] study showed an effect on $E$. coli, which correlates with the results registrated in our study.

Işcan et al.'s [29] study has revealed that $\alpha$-phellandrene, the major compound in the Eos belonging to Saudia Arabia, Morocco, and Syria (20.03-30.54\%), has a weak antibacterial activity toward several bacterial strains such as $S$. aureus (MRSA), E. coli, and $P$. aeruginosa at a concentration that varies from 1 to $>4 \mathrm{mg} / \mathrm{ml}$. It was also mentioned that $\alpha$-phellandrene could contribute to the antibacterial effect [30]. The $\beta$-pinene present in the Eos of the different countries studied with a percentage ranging from 4.53-9.77\% and $\alpha$-pinene present in Moroccan (6.29\%) and Syrian (4.07\%) Eos have showed an important inhibitory activity of $S$. aureus with an MIC value equal to $20 \mu \mathrm{l} / \mathrm{ml}$ [31].

The research of Saad and Muller [23] shows that the hydroxyl group present on the thymol is responsible for the antimicrobial activity. Mosolygó et al. [32] have shown that the thymol, a monoterpene present in the essential oil of India (4.64\%), Saudi Arabia (8.39\%), and Morocco (7\%), exhibits an antibacterial activity on both $S$. aureus and E. coli, and the MIC obtained was, respectively, 0.31 and $5 \mathrm{mg} / \mathrm{ml}$. It was also reported that the thymol causes widening of the cell membrane which leads to a passive diffusion of ions between the spread phospholipids toward the external area $[3,33]$.

The $\beta$-cymene, a carvacrol precursor of one of the major compounds present in all samples tested with a percentage between 12.31 and $23.82 \%$, has an important affinity to the liposomal membrane which causes its extension [34], and it was also found that cymene has no significant effect on protein synthesis in $E$. coli while a significant effect was observed on motility decreasing [35].

\section{Conclusions}

The chemical compounds identified in this work using GCMS were obtained by hydrodistillation followed by a study of the chemical variation and an evaluation of their antibacterial effect. Despite the geographical distribution of NS seeds, a great similarity was observed in oil composition and also on the activity exhibited on multidrug-resistant bacteria. Gram-positive organisms were generally more sensitive to Eos than gram-negative organisms. Thus, NS Eos provide a rich source of phytochemical compounds that could be used in the treatment of different infectious diseases caused by microbial agents.

\section{Data Availability}

All data used to support the finding of our study are available online and from the corresponding author upon request.

\section{Conflicts of Interest}

The authors declare no conflicts of interest.

\section{Acknowledgments}

The authors in this work would like to express their appreciation to Mr. BERRAH Aboulkacem for providing his help with the English language and Mr. BEKKOUCH Oussama for his technical support.

\section{References}

[1] S. N. Bakal, S. Bereswill, and M. M. Heimesaat, "Finding novel antibiotic substances from medicinal plants-antimicrobial properties of Nigella sativa directed against multidrug resistant bacteria," European Journal of Microbiology and Immunology, vol. 7, no. 1, pp. 92-98, 2017.

[2] S. Shrivastava and P. Shrivastava, "World health organization releases global priority list of antibiotic-resistant bacteria to guide research, discovery, and development of new antibiotics," Journal of Medical Society, vol. 32, no. 1, pp. 76-77, 2018.

[3] S. W. Schuff, W. Rasool, K. Shafi et al., "A comprehensive review of the antibacterial, antifungal and antiviral potential of essential oils and their chemical constituents against drugresistant microbial pathogens," Microbial Pathogenesis, vol. 134, no. March, p. 103580, 2019.

[4] H. Zuridah, A. R. M. Fairuz, A. H. Z. Zakri, and M. N. A. Rahim, "In vitro Antibacterial Activity of Nigella sativa against Staphylococcus aureus, Pseudomonas 
aeruginosa, Klebsiella pneumoniae, Escherichia coli and Bacillus cereus," Asian Journal of Plant Sciences, vol. 7, 2008.

[5] H. Mahmoudvand, A. Sepahvand, S. Jahanbakhsh et al., "Evaluation of antifungal activities of the essential oil and various extracts of Nigella sativa and its main component, thymoquinone against pathogenic dermatophyte strains," Journal de Mycologie Médicale, vol. 24, no. 4, pp. e155-e161, 2014.

[6] A. A. Adeneye, "Subchronic and chronic toxicities of African medicinal plants," in Toxicological Survey of African Medicinal PlantsElsevier, Amsterdam, Netherlands, 2014.

[7] A. Ahmad, A. Husain, M. Mujeeb et al., "A review on therapeutic potential of Nigella sativa: a miracle herb," Asian Pacific Journal of Tropical Biomedicine, vol. 3, no. 5, pp. 337-352, 2013.

[8] S. E. Priani, S. S. Maulidina, F. Darusman et al., "Development of self nanoemulsifying drug delivery system for black seed oil (Nigella sativa L.)," Journal of Physics: Conference Series, vol. 1469, no. 1, p. 012022, 2020.

[9] M. Fennane, M. Ibn Tattou, J. Mathez, A. E. Ouyahya, and J. Oualidi, "Pteridophyta, gymnospermae, angiospermae (LauraceaeNeuradaceae): manuel de détermination des plantes vasculaires," Flore Pratique du Maroc, vol. 1, 1999.

[10] M. Fennane, M. Ibn Tattou, J. Mathez, A. E. Ouyahya, and J. Oualidi, “Angiospermae (Leguuminosae-Lentibulariaceae): manuel de détermination des plantes vasculaires," Flore Pratique du Maroc, vol. 2, 2007.

[11] M. Fennane, M. Ibn Tattou, A. E. Ouyahya, and J. Oualidi, "Monocotyledones: Manuel de Détermination des plantes vasculaires," Flore Pratique du Maroc, vol. 3, 2014.

[12] E. Jahandiez and R. Maire, Catalogue des plantes du Maroc, Vol. 1, Minerva, Alger et Lechevalier, Paris, France, 1931.

[13] E. Jahandiez and R. Maire, Catalogue des plantes du Maroc, Vol. 2, Minerva, Alger et Lechevalier, Paris, France, 1932.

[14] E. Jahandiez and R. Maire, Catalogue des plantes du Maroc, Vol. 3, Minerva, Alger et Lechevalier, Paris, France, 1934.

[15] M. Balouiri, M. Sadiki, and S. K. Ibnsouda, "Methods for in vitro evaluating antimicrobial activity: a review," Journal of Pharmaceutical Analysis, vol. 6, no. 2, pp. 71-79, 2016.

[16] C. M. Mare and J. L. Markham, "A new method for determining the minimum inhibitory concentration of essential oils," Journal of Applied Microbiology, vol. 84, no. 4, pp. 538-544, 1998.

[17] S. D. Sarker and L. Nahar, "Microtitre plate-based antibacterial assay incorporating resazurin as an indicator of cell growth, and its application in the in vitro antibacterial screening of phytochemicals," Methods, vol. 42, no. 4, pp. 321-324, 2007.

[18] S. Bourgou, A. Pichette, B. Marzouk, and J. Legault, "Bioactivities of black cumin essential oil and its main terpenes from Tunisia," South African Journal of Botany, vol. 76, no. 2, pp. 210-216, 2010.

[19] B. Hoque, B. Aoumeur, Y. Brahim, and C. Farid, "Chemical variability of the leaf oil of 113 hybrids from citrus clementina (commun) $\times$ citrus deliciosa (willow leaf)," Flavour and Fragrance, vol. 23, pp. 152-163, 2008.

[20] B. Nickavar, F. Mojab, and K. Javidnia, "Chemical composition of the fixed and volatile oils of nigella sativa L. From Iran," Zeitschrift für Naturforschung C, vol. 58, no. 9-10, pp. 629-631, 2003.

[21] S. Koets, "Essential oils: their antibacterial properties and potential applications in foods-a review," International Journal of Food Microbiology, vol. 94, no. 3, pp. 223-253, 2004.
[22] M. Oussalah and S. Caillet, "Mechanism of action of Spanish oregano, Chinese cinnamon, and savory essential oils against cell membranes and walls of Escherichia coli O157:H7 and Listeria monocytogenes," Journal of Food Protection, vol. 69, no. 5, pp. 1046-1055, 2006.

[23] N. Y. Saad and C. D. Muller, "Major bioactivities and mechanism of action of essential oils and their components," Flavour and Fragrance Journal, vol. 28, no. 5, pp. 269-279, 2013.

[24] A. Man, L. Santacroce, R. Jacob, L. Santacroce, and L. Man, "Activity of six essential oils against a group of human pathogens: a comparative study," vol. 8, no. 1, pp. 15-11, 2019.

[25] R. R. Mendonça-Filho, "Bioactive phytocompounds: new approaches in the phytosciences," in Modern Phytomedicine: Turning Medicinal Plants Into Drugs, pp. 1-24, Wiley, Hoboken, NJ, USA, 2006.

[26] M. T. Lobstein, R. A. Khan, and I. Shukla, “Antimicrobial activity of nigella sativa linn. Seed oil against multi-drug resistant bacteria from clinical isolates," Indian Journal of Natural Products and Resources, vol. 7, no. 1, pp. 10-14, 2008.

[27] S. Deloer and M. Bari, "Antibacterial properties of essential oil (EO) extracted from nigella sativa linn. (Black cumin) and its application against Vibrio cholerae in ground chicken meat," Bangladesh Journal of Microbiology, vol. 34, no. 2, pp. 55-60, 2019.

[28] S. Singh, S. S. Das, G. Singh, C. Schuff, M. P. de Lampasona, and C. A. N. Catalán, "Composition, in vitro antioxidant and antimicrobial activities of essential oil and oleoresins obtained from black cumin seeds (Nigella sativa L.)," BioMed Research International, vol. 2014, Article ID 918209, 10 pages, 2014.

[29] G. Işcan, N. Kirimer, F. Demirci, B. Demirci, Y. Noma, and K. H. C. Başer, "Biotransformation of (-)-(R)- $\alpha$-phellandrene: antimicrobial activity of its major metabolite," Chemistry and Biodiversity, vol. 9, no. 8, pp. 1525-1532, 2012.

[30] Y. Q. Cui, X. H. Cui, Y. Zhu, Q. Zhang, and P. Nan, "Chemical composition and antimicrobial activity of volatile oil of six gymnosperm species leaves from Shanghai," in Proceedings of the 2nd International Conference on Bioinformatics and Biomedical Engineering, iCBBE 2008, pp. 4573-4577, Shanghai, China, May 2008.

[31] A. M. Leite, E. Lima, E. L. De Oliveira De Souza et al., "Inhibitory effect of beta-pinene, alpha-pinene and eugenol on the growth of potential infectious endocarditis causing Grampositive bacteria," Revista Brasileira de Ciências Farmacêuticas, vol. 43, no. 1, pp. 121-126, 2007.

[32] T. Mosolygó, A. Mouwakeh, M. H. Ali et al., "Bioactive compounds of Nigella sativa essential oil as antibacterial agents against Chlamydia trachomatis D," Microorganisms, vol. 7, no. 9, pp. 370-378, 2019.

[33] D. Trombetta, F. Castelli, M. G. Sarpietro et al., "Mechanisms of antibacterial action of three monoterpenes," Antimicrobial Agents and Chemotherapy, vol. 49, no. 6, pp. 2474-2478, 2005.

[34] A. Ultee, R. A. Slump, G. Steging, and E. J. Smid, "Antimicrobial activity of carvacrol toward Bacillus cereus on rice," Journal of Food Protection, vol. 63, no. 5, pp. 620-624, 2000.

[35] S. A. Burt, R. V. Zee, A. Ad Graaff et al., "Carvacrol induces heat shock protein 60 and inhibits synthesis of flagellin in Escherichia coli O157:H7," Applied and Environmental Microbiology, vol. 73, no. 14, pp. 4484-4490, 2007. 